\title{
Erratum: Palma-Bautista et al. Resistance Mechanisms to 2,4-D in Six Different Dicotyledonous Weeds Around the World. Agronomy 2020, 10, 566
}

\author{
Candelario Palma-Bautista ${ }^{1}$ (D), Antonia M. Rojano-Delgado ${ }^{1}$, Ignacio Dellaferrera ${ }^{2,3}$ (D) Jesús M. Rosario ${ }^{1}$, \\ Mario R. Vigna ${ }^{4}$, Joel Torra ${ }^{5, *(D)}$ and Rafael de Prado ${ }^{1}$ (D)
}

check for updates

Citation: Palma-Bautista, C.;

Rojano-Delgado, A.M.; Dellaferrera,

I.; Rosario, J.M.; Vigna, M.R.; Torra, J.; de Prado, R. Erratum: Palma-Bautista et al. Resistance Mechanisms to 2,4-D in Six Different Dicotyledonous Weeds Around the World. Agronomy 2020, 10, 566. Agronomy 2021, 11, 1081 https:/ / doi.org/10.3390/agronomy 11061081

Received: 7 May 2021

Accepted: 24 May 2021

Published: 27 May 2021

Publisher's Note: MDPI stays neutral with regard to jurisdictional claims in published maps and institutional affiliations.

Copyright: (c) 2021 by the authors Licensee MDPI, Basel, Switzerland. This article is an open access article distributed under the terms and conditions of the Creative Commons Attribution (CC BY) license (https:// creativecommons.org/licenses/by/ $4.0 /)$.
1 Department of Agricultural Chemistry and Edaphology, University of Cordoba, 14071 Cordoba, Spain; candelariopalma@gmail.com (C.P.-B.); arakidonis@hotmail.com (A.M.R.-D.); jmrs.agroinro@yahoo.com (J.M.R.); qe1pramr@uco.es (R.d.P.)

2 Faculty of Agricultural Sciences, National University of the Litoral, Esperanza 3080, Argentina; idellaferrera@gmail.com

3 National Scientific and Technical Research Council, CABA, C1425FQB, Godoy Cruz 2290, Argentina

4 Agricultural Experimental Station (EEA), National Institute of Agricultural Technology (INTA) Bordenave, Bordenave, Buenos Aires 8187, Argentina; vigna.mario@inta.gob.ar

5 Department of Horticulture, Botany and Gardening, Agrotecnio, University of Lleida, 25198 Lleida, Spain

* Correspondence: joel.torra@udl.cat; Tel.: +34-973702318

The authors would like to make the following correction to the published paper [1]:

Revise the chemical formula in the first sentence of Section 3.4. 2,4-D Plant Metabolism from " ${ }^{14} \mathrm{C}-2,4-\mathrm{D}$ " into "2,4-D", since the experiments were done with non-radiolabelled herbicide, as explained in the Methods Section.

The authors and Agronomy Editorial Office would like to apologize for any inconvenience caused to the readers by these changes. The changes do not affect the scientific results. The published version will be updated on the article webpage, with a reference to this erratum.

\section{Reference}

1. Palma-Bautista, C.; Rojano-Delgado, A.M.; Dellaferrera, I.; Rosario, J.M.; Vigna, M.R.; Torra, J.; de Prado, R. Resistance Mechanisms to 2,4-D in Six Different Dicotyledonous Weeds Around the World. Agronomy 2020, 10, 566. [CrossRef] 